\title{
Capsule Commentary for Warsame et al., Responsibilities, Strategies and Practice Factors in Clinical Cost Conversations: a US Physician Survey
}

\author{
Ksenia Gorbenko, $\mathrm{PhD}^{1,2}$, Himanshu Joshi, MBBS, MPH, PhD ${ }^{1,2}$, and Serena Zhan, $\mathrm{MS}^{1,2}$ \\ 'Department of Population Health Science and Policy, Icahn School of Medicine at Mount Sinai, Institute for Health Care Delivery Science, New \\ York, NY, USA; ${ }^{2}$ Institute for Health Care Delivery Science, Mount Sinai Health System, New York, NY, USA.
}

$\mathrm{J}$ Gen Intern Med 35(7):2251

DOI: $10.1007 / \mathrm{s} 11606-020-05842-\mathrm{x}$

(c) Society of General Internal Medicine 2020

$\mathrm{P}$ hysician decisions are pivotal and impact $80 \%$ of all health care expenditures and overall health care quality. ${ }^{1}$ With the passing of the Affordable Care Act, value-based payment models have put pressure on health care organizations and providers to deliver quality care, reduce costs, and increase patient satisfaction. Understanding evolving physician perspectives on cost can provide helpful guidance on policy implementation.

Warsame et al. ${ }^{2}$ report the findings from a national survey describing the physician perspective on costs of care, costconsciousness, and strategies on cost-containment. The comparative analysis presented in this study is based on contrasting results of two surveys, conducted in 2012 and 2017. The growing integration of the health care system in the USA in the last decade has increased hospital mergers and acquisitions and made health care systems even more important players than they once were. This may explain the finding that more physicians attributed responsibility for costs to pharmaceutical companies, hospitals, and health systems and showed less enthusiasm towards patient-focused cost-containment strategies such as high deductible plans. Another important finding was that, even when controlling for demographics and years in practice, democratic/ independent party affiliation was a significant predictor of physician cost-consciousness. The question about party affiliation changed between 2012 and 2017 surveys from a general question about political ideology (liberal or conservative) to a question about party affiliation. One can imagine that while political ideology captures political belief, various other factors can influence one's political party affiliation (e.g., state of residence, family tradition, and religion). Therefore, it could be worthwhile to analyze both in the next iteration of the survey.

Published online April 22, 2020
A thorough discussion of the survey design and underlying constructs used to perform unbiased population estimation and inference would be a welcome addition. We encourage journals to publish online supplements that describe the statistical analysis so that other researchers can undertake similar studies. The finding that a discussion about costs prompted a change in physician decisions in about half of all cases (56\%) highlights the need for comparative clinical effectiveness research $^{3}$ and a process to incorporate discussions of cost into clinical practice through shared decision-making tools. In addition, medical education should incorporate tenets of value-based medicine and health care macroeconomics.

Corresponding Author: Ksenia Gorbenko, $\mathrm{PhD}$; Department of Population Health Science and Policy, Icahn School of Medicine at Mount Sinai, Institute for Health Care Delivery Science, New York, NY, USA (e-mail: ksenia.gorbenko@mssm.edu).

\section{Compliance with Ethical Standards:}

Conflict of Interest: The authors declare that they do not have a conflict of interest.

\section{REFERENCES}

1. Wynia MK, Cummins DS, VanGeest JB, Wilson IB. Physician manipulation of reimbursement rules for patients: Between a rock and a hard place. J Am Med Assoc. 2000;283(14):1858-1865. https://doi.org/10. 1001/jama.283.14.1858

2. Warsame R, Riordan L, Jenkins S, et al. Responsibilities, Strategies and Practice Factors in Clinical Cost Conversations: A US Physician Survey. $J$ Gen Intern Med. 2020. https://doi.org/10.1007/s11606-020-05807-0

3. Institute of Medicine (US). Redesigning the Clinical Effectiveness Research Paradigm: Innovation and Practice-Based Approaches: Workshop Summary. In: Olsen L, McGinnis J, eds. Roundtable on Value \& Science-Driven Health Care. National Academies Press (US); 2010. https://doi.org/10. $17226 / 12197$

Publisher's Note: Springer Nature remains neutral with regard to jurisdictional claims in published maps and institutional affiliations. 